\title{
Implementasi algoritma Floyd dalam menentukan rute terpendek transportasi pariwisata
}

\section{The implementation of Floyd algorithm in determining the shortest routes for tourism transportation}

\author{
Utti Marina Rifanti a, Bongga Arifwidodo ${ }^{b}$ \\ a,b Teknik Telekomunikasi, Institut Teknologi Telkom Purwokerto, Purwokerto, Indonesia \\ email:amarina@ittelkom-pwt.ac.id, bbongga@ ittelkom-pwt.ac.id
}

\begin{tabular}{l} 
I N F O A R T I K E L \\
\hline Sejarah artikel: \\
Menerima 17 Mei 2019 \\
Revisi 6 Agustus 2019 \\
Diterima 12 September 2019 \\
Online 13 September 2019
\end{tabular}

Kata kunci:

algoritma Floyd

Banyumas

pariwisata

rute terpendek

teori graf

\section{Keywords: \\ Floyd algorithm \\ Banyumas \\ graph teory \\ shortest route}

tourism

\section{Style APA dalam menyitasi} artikel ini:

Rifanti, U. M., \&

Arifwidodo, B. (2019). Implementasi algoritma Floyd dalam menentukan rute terpendek transportasi pariwisata. Register: Jurnal Ilmiah Teknologi Sistem Informasi, 5(2), 140-151.

\begin{abstract}
ABSTRAK
Pariwisata merupakan penyumbang kontribusi yang cukup signifikan bagi kemajuan perekonomian suatu daerah. Sarana transportasi umum khusus pariwisata dapat menjadi penyokong kemajuan pariwisata. Sarana transportasi tersebut diperuntukkan bagi para wisatawan yang ingin mengunjungi objekobjek wisata, sehingga mereka dapat melakukan perjalanan wisata dengan mudah, efektif, dan efisien. Dalam pembangunan rute transportasi yang efektif dan efisien, dibutuhkan kontribusi ilmu pengetahuan yang mempelajari hal tersebut, misalnya teori graf. Teori graf mempunyai berbagai aplikasi dalam kehidupan manusia, termasuk bidang transportasi. Salah satu algoritma dalam teori graf yang dapat digunakan untuk mengoptimalkan rute suatu model transportasi adalah algoritma Floyd. Studi kasus dari penelitian ini dilakukan di Kabupaten Banyumas. Penelitian ini bertujuan untuk merancang rute bus wisata yang dapat menjangkau objek-objek wisata di Kabupaten Banyumas dengan rute terpendek menggunakan algoritma Floyd. Hasil penelitian ini diperoleh rute yang dapat dilalui oleh bus wisata agar dapat menempuh jarak terpendek. Perancangan rute transportasi ini diharapkan dapat meningkatkan kunjungan wisatawan ke Kabupaten Banyumas, baik wisatawan asing maupun wisatawan nusantara.
\end{abstract}

\section{ABSTRACT}

Tourism is a significant contributor to the development of the regional economy. Public transportation specially designed for tourism may well support the development of tourism. Such means of transportation is designed for tourists who would like to visit tourism objects so that they can travel easily, effectively, and efficiently. In developing effective and efficient transportation routes, the contribution of science, such as graph theory, is necessary. Graph theory has been applied in various fields of human life, including in the field of transportation. One of the algorithms in the graph theory that can be used to optimize the route of a transportation model is Floyd algorithm. This research was a case study in Banyumas Regency. It was aimed at designing tour bus routes heading for the tourism objects in Banyumas Regency by displaying the shortest routes using Floyd algorithm. Through this research, it was obtained the shortest routes that could be traveled by tour buses. The routes were expected to increase the number of visitors, both foreign and domestic tourists, to Banyumas Regency.

(c) 2019 Register: Jurnal Ilmiah Teknologi Sistem Informasi. Semua hak cipta dilindungi undang-undang.

\section{Pendahuluan}

Pariwisata merupakan salah satu pendorong utama perekenomian negara maupun dunia, karena sektor pariwisata mampu memberikan devisa yang cukup besar bagi negara, serta mampu memperluas lapangan pekerjaan dan memperkenalkan budaya negara tersebut. Wilayah ASEAN (Association of 
Southeast Asian Nations) seringkali disebut "Surga Wisata" karena kekayaan yang melimpah di bidang pariwisata. Negara dengan tujuan utama pariwisata di ASEAN di antaranya adalah Indonesia, Thailand, Malaysia, Singapura, dan Filipina (Sabon, Perdana, Koropit, \& Pierre, 2018). Menurut data dari Badan Pusat Statistik (BPS) tahun 2018, tercatat total kunjungan wisatawan mancanegara ke Indonesia adalah 15.810 .305 orang (BPS, 2019). Bidang kepariwisataan menyumbang Produk Domestik Bruto (PDB) nasional sebesar 5,25\% pada 2018. Pada 2016, sektor pariwisata menyumbang devisa sebesar 224 triliun rupiah (Kemenpar, 2019). Selain meningkatkan devisa, sektor pariwisata juga dapat menentukan jumlah kegiatan konsumsi dan investasi, sehingga dapat merangsang pertumbuhan sektor ekonomi lainnya (Santi, 2016).

Terdapat beberapa faktor pendukung pariwisata, di antaranya adalah faktor kelangkaan, kealamiahan, keunikan, pemberdayaan masyarakat, optimalisasi lahan, pemerataan, dan transportasi (Tambunan, 2009). Dari beberapa faktor tersebut, salah satu faktor yang dapat dioptimalkan adalah faktor transportasi. Cara untuk mengoptimalkan faktor transportasi adalah dengan membangun rute transportasi pariwisata yang efektif dan efisien bagi para wisatawan. Sarana transportasi yang memadai menjadi salah satu faktor yang mendukung kesuksesan sektor pariwisata suatu daerah. Salah satu contohnya adalah Singapura yang mempunyai sarana transportasi terkenal bernama MRT (Mass Rapid Transit). Adanya MRT yang menjangkau seluruh daerah di Singapura, para wisatawan pun tidak perlu khawatir lagi saat ingin menjelajahi daerah wisata kota tersebut (Roselina, 2016). Pembangunan rute transportasi yang efektif dan efisien, dibutuhkan kontribusi ilmu pengetahuan yang mempelajari hal tersebut. Salah satu bidang yang mempelajari hal tersebut adalah teori graf. Teori graf mempunyai berbagai aplikasi dalam kehidupan manusia, termasuk transportasi. Selain dapat digunakan untuk perancangan rute suatu mode transportasi, teori graf juga dapat digunakan untuk mencari jarak dari suatu tempat ke tempat lain. Algoritma dalam teori graf yang dapat digunakan untuk mengoptimalkan rute suatu mode transportasi adalah algoritma Floyd (Munir, 2010). Algoritma Floyd memiliki keunggulan yang tidak dimiliki oleh algoritma lainnya, salah satunya karena algoritma ini merupakan algoritma pemrograman yang dinamis (Darnita, Toyib, \& Rinaldi, 2017), sederhana dan mudah diimplementasikan (Hasibuan, 2016).

Studi kasus pada penelitian ini dilakukan di Kabupaten Banyumas karena wilayah tersebut memiliki keanekaragaman wisata, baik wisata alam, religi, maupun pendidikan. Selain itu, Kabupaten Banyumas merupakan salah satu daerah wisata yang sedang mengalami perkembangan cukup pesat. Hal ini terlihat dari adanya peningkatan jumlah objek wisata, dari 10 objek wisata tahun 2002 menjadi 14 objek wisata di tahun 2013 (Hermawati \& Hermawati, 2016). Kabupaten Banyumas merupakan salah satu wilayah di Provinsi Jawa Tengah dengan batas wilayah sebelah barat adalah Provinsi Jawa Barat, sebelah selatan dibatasi oleh pantai Samudera Hindia, sebelah timur dibatasi oleh Kabupaten Wonosobo, dan sebelah utara dibatasi oleh Kabupaten Pekalongan, Pemalang, Tegal, dan Brebes. Secara astronomis, Banyumas terletak antara $7^{\circ} 15^{\prime} 05^{\prime \prime}-7^{\circ} 37^{\prime} 10^{\prime \prime}$ LS dan antara $108^{\circ} 39^{\prime} 17^{\prime \prime}-109^{\circ} 27^{\prime} 15^{\prime \prime}$ BT. Kabupaten Banyumas terdiri atas 27 kecamatan dengan total wilayah berupa daratan seluas 1.327,59 $\mathrm{km}^{2}$ (Banyumas, 2017). Terdapat beberapa destinasi wisata yang ada di Kabupaten Banyumas, seperti Baturraden, Taman Andhang Pangrenan, The Village, Small World, Museum BRI, dan lain sebagainya. Akan tetapi, potensi wisata di Kabupaten Banyumas masih mengalami kendala karena kesiapan destinasi wisata yang belum optimal. Salah satu penyebabnya adalah keterbatasan fasilitas pendukung wisata, seperti sarana transportasi yang memudahkan pengunjung menuju objek wisata.

Oleh karena itu, dalam penelitian ini diusulkan penerapan teori graf untuk merancang rute bus wisata yang dapat menjangkau objek-objek wisata di Kabupaten Banyumas dengan efektif dan efisien menggunakan algoritma Floyd. Perancangan rute transportasi ini diharapkan dapat meningkatkan kunjungan wisatawan di Kabupaten Banyumas, baik wisatawan asing maupun wisatawan nusantara.

\section{State of the Art}

Berbagai penelitian telah dilakukan untuk mengkaji masalah yang berkaitan dengan pencarian rute terpendek. Beberapa di antaranya mengkaji pencarian rute terpendek dalam bidang pariwisata dan transportasi menggunakan algoritma Floyd. Ardiansyah dan Hakim (2012) mengembangkan aplikasi yang dapat menentukan rute terpendek di lokasi wisata Purbalingga dengan menggunakan algoritma Floyd, yang mana penentuan rute terpendek dilakukan dengan cara menghubungkan titik awal dengan objek wisata yang akan dituju. Namun, pada penelitian Ardiansyah dan Hakim (2012) belum dikaji Implementasi algoritma Floyd dalam menentukan rute terpendek transportasi ... $\quad$ http://doi.org/10.26594/register.v5i2.1683 (C) 2019 Register: Jurnal IImiah Teknologi Sistem Informasi. Semua hak cipta dilindungi undang-undang. 
mengenai rute terpendek yang menghubungkan antara suatu objek wisata ke objek wisata lainnya. Kriswanto, Bendi, dan Aliyanto (2014) melakukan penelitian tentang penentuan jarak terpendek untuk rute Bus Rapid Transit antarhalte di Kota Palembang dengan menggunakan algoritma Floyd. Ningrum dan Andrasto (2016) mengkaji tentang penerapan algoritma Floyd-Warshall dalam pemodelan rute wisata di Semarang, tetapi dalam penelitian ini belum dijelaskan secara rinci proses cara kerja algoritma Floyd-Warshall.

Selain itu juga terdapat penelitian yang mengkaji tentang rute terpendek di bidang pariwisata dan transportasi menggunakan algoritma Dijkstra. Gusmão, Pramono, dan Sunaryo (2013) menggunakan algoritma Dijkstra untuk menentukan rute terpendek. Hasil dari penentuan rute terpendek tersebut ditampilkan melalui sistem informasi geografis yang berbasis web (Gusmão, Pramono, \& Sunaryo, 2013). Indiarto dan Somantri (2017) mengembangkan aplikasi informasi penjadwalan dan rute terpendek yang dilalui oleh Bus Rapid Transit (BRT) di Semarang menggunakan algoritma Dijkstra. Mustika, Ginardi, dan Munif (2017) mengkaji tentang rute angkutan Trans Sarbagita di Bali menggunakan algoritma Dijkstra. Rifanti (2017) dalam penelitiannya mengusulkan penentuan rute terbaik untuk mengurangi kemacetan lalu lintas di Purwokerto. Purwokerto merupakan salah satu wilayah yang ada di Kabupaten Banyumas, Jawa Tengah. Rifanti (2017) mengambil beberapa titik rawan macet di Purwokerto untuk dikaji lebih lanjut agar diperoleh rute terbaik yang dapat dilalui oleh warga sekitar di Purwokerto. Namun, Rifanti (2017) belum dikaji mengenai rute wisata di Purwokerto, melainkan hanya tentang rute transportasi untuk meminimalisasi kemacetan lalu lintas.

Selain penelitian yang mengkaji tentang pencarian rute terpendek tersebut, terdapat beberapa penelitian dalam bidang pariwisata. Salah satunya adalah penelitian yang mengkaji tentang potensi angkutan umum, khususnya pariwisata di Yogyakarta. Basuki dan Setiadi (2015) menyimpulkan bahwa angkutan khusus pariwisata sangat berpotensi untuk diwujudkan di Yogyakarta. Namun, Basuki dan Setiadi (2015) belum mengkaji tentang rute-rute potensial wisata di Yogyakarta.

Berdasarkan beberapa penelitian tersebut, pada penelitian ini akan mengkaji masalah pencarian rute terpendek yang dapat dilalui oleh bus wisata di Kabupaten Banyumas yang menghubungkan satu objek wisata ke objek wisata lainnya menggunakan algoritma Floyd.

\section{Metode Penelitian}

Tabel 1. Data lokasi objek wisata

\begin{tabular}{cl}
\hline Halte & \multicolumn{1}{c}{ Objek Wisata } \\
\hline 1 & Stasiun Purwokerto \\
2 & Taman Andhang Pangrenan \\
3 & Balai Kemambang \\
& The Forest \\
4 & The Village \\
& Bukit Kendalisada \\
& Lokawisata Baturraden \\
5 & Taman Labirin \\
& Kebun Raya Baturraden \\
6 & Small World \\
7 & Caping Park \\
\hline
\end{tabular}

Penelitian ini dilakukan di Kabupaten Banyumas, Jawa Tengah, khususnya pada objek-objek wisata yang ada di daerah tersebut. Tujuan dari penelitian ini adalah membuat rancangan rute bus wisata yang dengan rute terpendek di Kabupaten Banyumas. Objek dari penelitian ini adalah objek-objek wisata yang ada di Kabupaten Banyumas dengan Stasiun Purwokerto sebagai titik awalnya. Langkah awal dalam penelitian ini adalah menentukan halte-halte yang akan dikunjungi oleh bus wisata. Halte diasumsikan berada di sekitar objek wisata, sehingga setelah turun dari bus wisata, wisatawan dapat menjangkau objek wisata yang akan dituju dengan mudah. Beberapa objek wisata yang berdekatan (jarak kurang dari $1 \mathrm{~km}$ ) diasumsikan mempunyai satu halte. Data objek wisata dan halte ditampilkan dalam Tabel 1.

Langkah selanjutnya adalah menentukan graf berbobot dari setiap dua pasang halte sesuai dengan Tabel 1. Setiap graf merepresentasikan semua kemungkinan rute yang dapat dilewati dari 
setiap dua pasang halte. Dalam setiap graf, titik merepresentasikan halte awal dan beberapa titik persimpangan jalan yang dapat dilewati untuk menuju ke halte akhir. Sementara, sisi merepresentasikan jalan-jalan yang menghubungkan halte ke persimpangan jalan terdekat ataupun persimpangan jalan yang satu ke persimpangan jalan lainnya. Data yang digunakan adalah data primer dengan melakukan pengukuran langsung jarak dari titik awal (Stasiun Purwokerto) ke titik (halte) lainnya, pengukuran jarak juga didapatkan dari jarak antartitik menggunakan Google Maps. Jarak tersebut direpresentasikan sebagai bobot lintasan dalam graf. Kemudian, dari graf tersebut disusun sebuah matriks ketetanggaan yang menggambarkan jarak antartitik. Matriks ketetanggaan berisi bobot sisi yang menghubungkan dua titik. Jika bobot dari titik $\boldsymbol{v}_{\boldsymbol{i}}$ ke titik $\boldsymbol{v}_{\boldsymbol{j}}$ disimbolkan dengan $\boldsymbol{d}_{\boldsymbol{i} \boldsymbol{j}}$, bobot $\boldsymbol{d}_{\boldsymbol{i} \boldsymbol{j}}$ mempunyai 3 kemungkinan nilai, yaitu:

- $d_{i j}=0$, jika $i=j$

- $d_{i j}=\infty$, jika $i \neq j$ dengan $v_{i}$ tidak terhubung dengan $v_{j}$

- $d_{i j}=$ jarak antartitik, jika $i \neq j$ dengan $v_{i}$ terhubung dengan $v_{j}$

Setelah diperoleh matriks ketetanggaan, kemudian dicari rute terpendek antar titik menggunakan algoritma Floyd. Algoritma Floyd membandingkan semua kemungkinan lintasan untuk setiap pasang titik dalam graf dan kemudian melakukan pengujian dari kombinasi titik yang diperoleh tersebut. Algoritma Floyd menggunakan matriks berukuran $\boldsymbol{n} \times \boldsymbol{n}$ sebagai representasi dari sebuah graf, dengan $\boldsymbol{n}$ menyatakan banyaknya sisi (Setiawan, Kiftiah, \& Partiwi, 2017). Adapun langkahlangkah yang ditempuh untuk menentukan rute terpendek menggunakan algoritma Floyd adalah sebagai berikut. Misalkan, $\boldsymbol{W}_{\mathbf{0}}$ adalah matriks ketetanggaan. Secara umum penentuan lintasan terpendek untuk setiap pasangan titik menggunakan algoritma Floyd adalah sebagai berikut (Kriswanto, Bendi, \& Aliyanto, 2014):

a. $W=W_{0}$

b. Untuk $k=1$ hingga $n$, lakukan:

Untuk $i=1$ hingga $n$, lakukan:

Untuk $j=1$ hingga $n$, lakukan:

Jika $W[i . j]>W[i . k]+W[k . j]$, maka tukar $W[i . j]$ dengan $W[i . k]+W[k . j]$

c. $W^{*}=W$, dengan $W^{*}$ adalah matriks ketetanggaan minimal dan $w_{i j}^{*}=$ lintasan terpendek dari titik $v_{i}$ ke titik $v_{j}$.

\section{Hasil dan Pembahasan}

\subsection{Data jarak antarlokasi}

Tabel 2. Data rute Stasiun Purwokerto-Andhang Pangrenan

\begin{tabular}{cclc}
\hline No. & Lintasan (titik awal-titik akhir) & Nama Jalan yang Dilalui & Jarak (km) \\
\hline 1 & A - B & Jl. Pemuda & 0,7 \\
2 & B - C & Jl. Gatot Subroto & 1,2 \\
3 & C - D & Jl. Gatot Subroto & 0,6 \\
4 & B - E & Jl. Wiryaatmaja & 0,65 \\
5 & C - F & Jl. Merdeka & 0,6 \\
6 & D - G & Jl. Pierre Tendean & 0,65 \\
7 & E - F & Jl. Jend. Soedirman & 1,2 \\
8 & F - G & Jl. Jend. Soedirman & 0,45 \\
9 & G - H & Jl. Jend. Soedirman & 0,4 \\
10 & E - I & Jl. Pahlawan & 1,8 \\
11 & G - J & Jl. Perintis Kemerdekaan & 1,4 \\
12 & H - K & Jl. S. Parman & 1,7 \\
13 & I - J & Jl. Gerilya & 2,4 \\
14 & J - K & Jl. Gerilya & 0,35 \\
\hline
\end{tabular}

Ardana dan Saputra (2016) meneliti tentang penentuan rute bus Trans Semarang menggunakan algoritma Dijkstra. Pada penelitian Ardana dan Saputra (2016), koridor atau tempat pemberhentian yang akan dilalui oleh bus Trans Semarang telah ditentukan sebelumnya karena bus Trans Semarang sudah beroperasi. Namun, pada penelitian Ardana dan Saputra (2016), halte atau tempat pemberhentian ditentukan seperti yang tercantum pada Tabel 1, karena belum adanya bus wisata yang beroperasi di Kabupaten Banyumas. Data jarak antarlokasi diperoleh dari Google Maps. Pada 
penelitian Rifanti (2017) tentang penentuan rute terbaik untuk menghindari kemacetan, bobot graf yang digunakan berupa kepadatan kendaraan yang ada di ruas jalan. Sementara, pada pembahasan ini, bobot sisi diperoleh dari data jarak antarlokasi. Titik merepresentasikan halte awal dan beberapa titik persimpangan jalan yang dapat dilewati untuk menuju ke halte akhir. Pada Tabel 2, Tabel 3, Tabel 4, dan Tabel 5, titik dinotasikan dengan huruf A, B, C, dan seterusnya. Data tersebut digunakan untuk mengetahui rute yang akan dilalui untuk menuju ke objek wisata tertentu. Adapun jarak antar halte disajikan dalam Tabel 2, Tabel 3, Tabel 4, dan Tabel 5.

Tabel 3. Data rute Andhang Pangrenan-Balai Kemambang

\begin{tabular}{cclc}
\hline No. & Lintasan (titik awal-titik akhir) & Nama Jalan yang Dilalui & Jarak (km) \\
\hline 1 & A - B & Jl. Gerilya & 0,7 \\
2 & A - C & Jl. S. Parman & 1,5 \\
3 & B - D & Jl. Perintis Kemerdekaan & 1,4 \\
4 & C - D & Jl. Jend. Soedirman & 0,4 \\
5 & D - E & Jl. Jend. Soedirman & 0,45 \\
6 & D - G & Jl. Pierre Tendean & 0,65 \\
7 & C - F & Jl. Jend Suprapto & 0,5 \\
8 & F - G & Jl. Gatot Subroto & 0,2 \\
9 & G - H & Jl. Gatot Subroto & 0,7 \\
10 & I- F & Jl. Overste Isdiman & 0,7 \\
11 & H- J & Jl. Ksatrian & 0,6 \\
12 & J - K & Jl. Karangkobar & 0,5 \\
13 & E - H & Jl. Merdeka & 0,8 \\
14 & I- J & Jl. Dr. Angka & 1,5 \\
\hline
\end{tabular}

Tabel 4. Data rute Balai Kemambang - The Village

\begin{tabular}{cclc}
\hline No. & Lintasan (titik awal-titik akhir) & Nama Jalan yang Dilalui & Jarak (km) \\
\hline 1 & A - C & Jl. Karangkobar & 0,3 \\
2 & B - C & Jl. Ringintirto & 0,8 \\
3 & C - D & Jl. Brigjen Encung & 0,95 \\
4 & D - E & Jl. Pol. Soemarto & 1,1 \\
5 & C - F & Jl. Jatisari & 1,1 \\
6 & B - G & Jl. H.R. Bunyamin & 1,2 \\
7 & E - F & Jl. Riyanto & 1,2 \\
8 & F - G & Jl. Riyanto & 0,5 \\
9 & E - H & Jl. Letjen Pol Suparto & 1,2 \\
10 & G - I & Jl. H.R. Bunyamin & 1,5 \\
11 & H - I & Jl. Moh. Besar & 1,3 \\
12 & I- J & Jl. Raya Baturraden & 1,8 \\
\hline
\end{tabular}

\subsection{Pencarian rute terpendek}

Tabel 5. Data rute Caping Park - Stasiun Purwokerto

\begin{tabular}{cclc}
\hline No. & Lintasan (titik awal-titik akhir) & Nama Jalan yang Dilalui & Jarak (km) \\
\hline 1 & A - B & Jl. Raya Baturraden Barat & 1,7 \\
2 & B - C & Jl. R. Soepeno & 6,7 \\
3 & B - D & Jl. Letjen Pol Suparto & 5,5 \\
4 & C - D & Jl. Kamandaka & 0,9 \\
5 & D - E & Jl. Kober & 1,5 \\
\hline
\end{tabular}

Penentuan rute terpendek dilakukan dengan prosedur yang telah dijelaskan pada bagian Metode Penelitian. Langkah pertama adalah mengonstruksi semua kemungkinan rute yang akan dilalui dalam sebuah graf berbobot. Penyusunan graf berbobot didasarkan pada data jarak yang tercantum pada Tabel 2 hingga Tabel 5 sedemikian sehingga akan diperoleh empat graf berbobot. Graf berbobot pertama menggambarkan semua kemungkinan rute yang dapat dilalui dari Stasiun Purwokerto (Halte 1) menuju lokasi halte objek wisata pertama, yaitu Taman Andhang Pangrenan (Halte 2). Graf berbobot yang menggambarkan semua kemungkinan rute yang dapat dilalui dari Halte 1 menuju Halte 2 tercantum dalam Gambar 1 selanjutnya disebut Graf 1. 


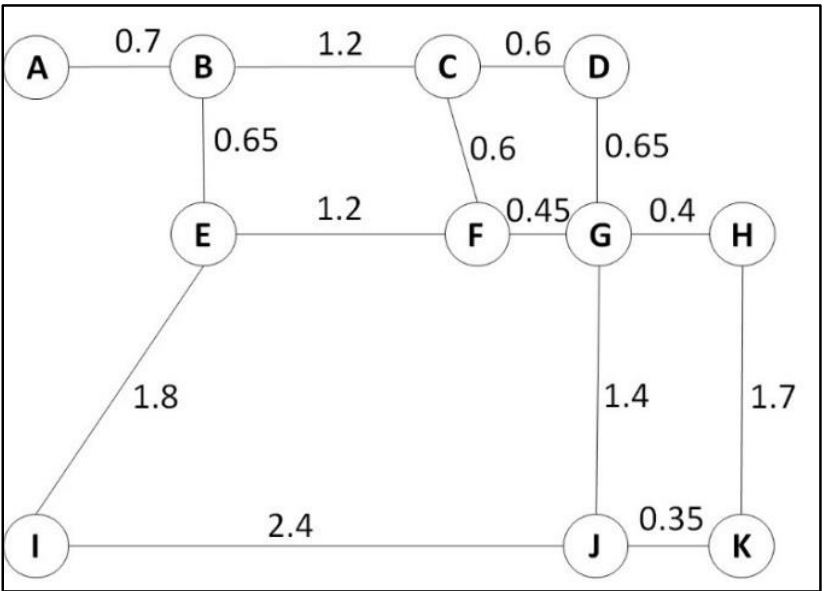

Gambar 1. Graf berbobot Halte 1 - Halte 2

Graf berbobot kedua menggambarkan semua kemungkinan rute yang dapat dilalui dari Taman Andhang Pangrenan (Halte 2) menuju lokasi halte objek wisata yang kedua, yaitu Balai Kemambang (Halte 3). Graf berbobot yang menggambarkan semua kemungkinan rute yang dapat dilalui dari Halte 2 menuju Halte 3 tercantum dalam Gambar 2 selanjutnya disebut Graf 2.

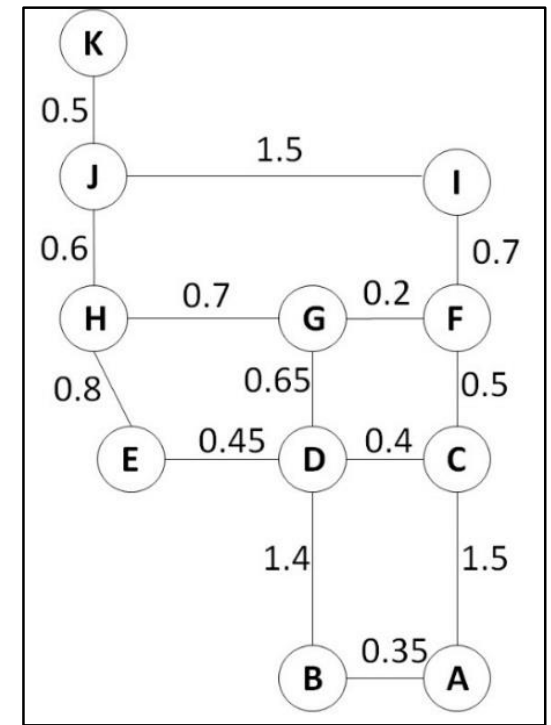

Gambar 2. Graf berbobot Halte 2 - Halte 3

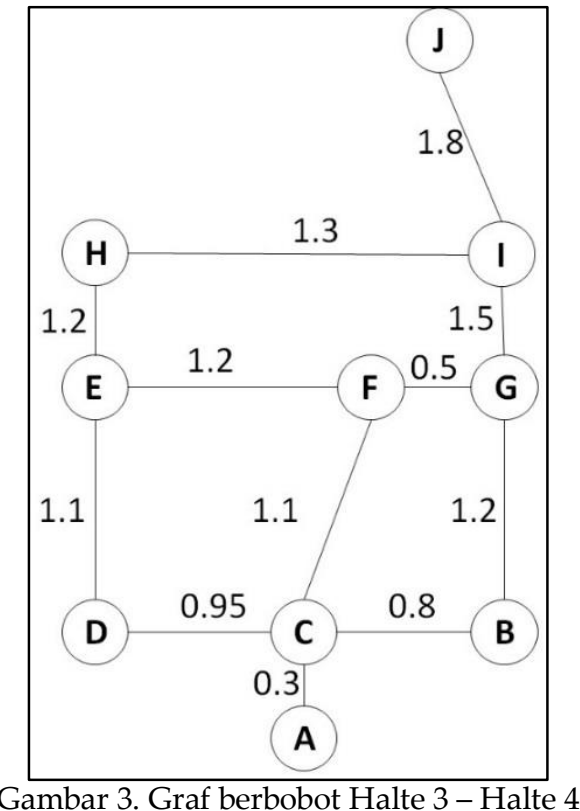




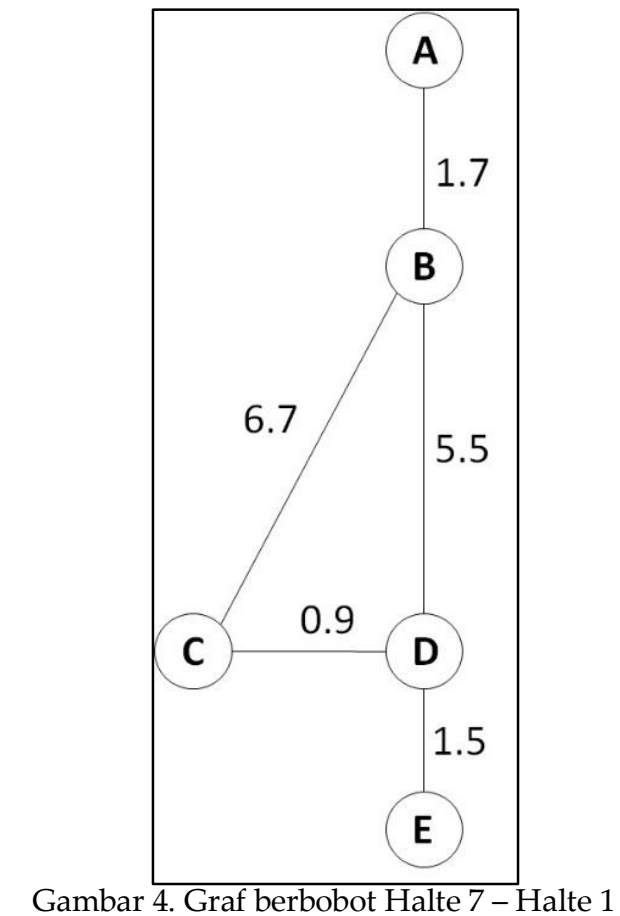

Graf berbobot ketiga menggambarkan semua kemungkinan rute yang dapat dilalui dari halte Balai Kemambang (Halte 3) menuju lokasi halte objek wisata yang ketiga, yaitu The Village, The Forest, Bukit Kendalisada (Halte 4). Graf berbobot yang menggambarkan semua kemungkinan rute yang dapat dilalui dari Halte 3 menuju Halte 4 tercantum dalam Gambar 3 selanjutnya disebut Graf 3.

Karena hanya terdapat satu rute yang dapat dilalui dari Halte 4 menuju Halte 5, Halte 6, dan Halte 7, maka tidak dilakukan proses pencarian rute terpendek dari Halte 4 menuju Halte 7. Graf berbobot keempat menggambarkan semua kemungkinan rute yang dapat dilalui dari halte Caping Park (Halte 7) menuju lokasi halte tujuan akhir, yaitu Stasiun Purwokerto (Halte 1). Graf berbobot yang menggambarkan semua kemungkinan rute yang dapat dilalui dari Halte 7 menuju Halte 1 tercantum dalam Gambar 4 selanjutnya disebut Graf 4.

Pada penelitian yang telah dilakukan oleh Ardana dan Saputra (2016), penentuan rute terpendek bus Trans Semarang dilakukan menggunakan algoritma Dijkstra. Algoritma Dijkstra menggunakan sistem pencarian rute single source shortest path, yaitu mencari rute dari suatu titik awal ke semua titik yang lain. Sementara, dalam pembahasan ini akan diuraikan cara penentuan rute terpendek graf menggunakan algoritma Floyd. Berbeda dengan algoritma Dijkstra, algoritma Floyd menggunakan sistem pencarian rute all pair shortest path, yaitu mencari rute terpendek dari semua kemungkinan pasangan titik. Setelah mengonstruksi graf berbobot, langkah selanjutnya adalah menentukan matriks ketetanggaan berdasarkan masing-masing graf berbobot yang tercantum pada Gambar 1 hingga Gambar 4. Adapun matriks ketetanggaan dari Graf 1 pada Iterasi 0 atau iterasi awal ditampilkan pada Matriks 1.

\begin{tabular}{|c|c|c|c|c|c|c|c|c|c|c|c|}
\hline & $A$ & $B$ & $C$ & $D$ & $E$ & $F$ & $G$ & $H$ & $I$ & $J$ & $K$ \\
\hline$A$ & 0 & 0,7 & $\infty$ & $\infty$ & $\infty$ & $\infty$ & $\infty$ & $\infty$ & $\infty$ & $\infty$ & $\infty$ \\
\hline$B$ & 0,7 & 0 & 1,2 & $\infty$ & 0,65 & $\infty$ & $\infty$ & $\infty$ & $\infty$ & $\infty$ & $\infty$ \\
\hline$C$ & $\infty$ & 1,2 & 0 & 0.6 & $\infty$ & 0,6 & $\infty$ & $\infty$ & $\infty$ & $\infty$ & $\infty$ \\
\hline$D$ & $\infty$ & $\infty$ & 0,6 & 0 & $\infty$ & $\infty$ & 0,65 & $\infty$ & $\infty$ & $\infty$ & $\infty$ \\
\hline$E$ & $\infty$ & 0,65 & $\infty$ & $\infty$ & 0 & 1,2 & $\infty$ & $\infty$ & $\infty$ & $\infty$ & $\infty$ \\
\hline$F$ & $\infty$ & $\infty$ & 0,6 & $\infty$ & 1,2 & 0 & 0,45 & $\infty$ & $\infty$ & $\infty$ & $\infty$ \\
\hline$G$ & $\infty$ & $\infty$ & $\infty$ & 0,65 & $\infty$ & 0,45 & 0 & 0,4 & $\infty$ & 1,4 & $\infty$ \\
\hline$H$ & $\infty$ & $\infty$ & $\infty$ & $\infty$ & $\infty$ & $\infty$ & 0,4 & 0 & $\infty$ & $\infty$ & 1,7 \\
\hline$I$ & $\infty$ & $\infty$ & $\infty$ & $\infty$ & 1,8 & $\infty$ & $\infty$ & $\infty$ & 0 & 2,4 & $\infty$ \\
\hline$J$ & $\infty$ & $\infty$ & $\infty$ & $\infty$ & $\infty$ & $\infty$ & 1,4 & $\infty$ & 2,4 & 0 & 0,35 \\
\hline$K$ & $\infty$ & $\infty$ & $\infty$ & $\infty$ & $\infty$ & $\infty$ & $\infty$ & 1,7 & $\infty$ & 0.35 & 0 \\
\hline
\end{tabular}

Matriks 1. Matriks ketetanggaan dari Graf 1 pada Iterasi 0 
Untuk $i=1, k=2$, dan $j=3$ diketahui bahwa $W[1,3]=\infty$ dan $W[1,2]+W[2,3]=0,7+1,2=1,9$

sehingga diperoleh,

$$
W[1,3]>W[1,2]+W[2,3]
$$

oleh karena itu, pada iterasi selanjutnya, nilai $W[1,3]=1,9$. Adapun matriks ketetanggaan Graf 1 pada Iterasi 1 disajikan pada Matriks 2.

\begin{tabular}{|c|c|c|c|c|c|c|c|c|c|c|c|}
\hline & $A$ & $B$ & $C$ & $D$ & $E$ & $F$ & $G$ & $H$ & $I$ & $J$ & $K$ \\
\hline & 0 & 0,7 & 1,9 & $\infty$ & $\infty$ & $\infty$ & $\infty$ & $\infty$ & $\infty$ & $\infty$ & $\infty$ \\
\hline$B$ & 0,7 & 0 & 1,2 & $\infty$ & 0,65 & $\infty$ & $\infty$ & $\infty$ & $\infty$ & $\infty$ & $\infty$ \\
\hline$C$ & $\infty$ & 1,2 & 0 & 0,6 & $\infty$ & 0,6 & $\infty$ & $\infty$ & $\infty$ & $\infty$ & $\infty$ \\
\hline$D$ & $\infty$ & $\infty$ & 0.6 & 0 & $\infty$ & $\infty$ & 0,65 & $\infty$ & $\infty$ & $\infty$ & $\infty$ \\
\hline$E$ & $\infty$ & 0,65 & $\infty$ & $\infty$ & 0 & 1,2 & $\infty$ & $\infty$ & $\infty$ & $\infty$ & $\infty$ \\
\hline$F$ & $\infty$ & $\infty$ & 0,6 & $\infty$ & 1,2 & 0 & 0,45 & $\infty$ & $\infty$ & $\infty$ & $\infty$ \\
\hline$G$ & $\infty$ & $\infty$ & $\infty$ & 0,65 & $\infty$ & 0,45 & 0 & 0.4 & $\infty$ & 1,4 & $\infty$ \\
\hline$H$ & $\infty$ & $\infty$ & $\infty$ & $\infty$ & $\infty$ & $\infty$ & 0,4 & 0 & $\infty$ & $\infty$ & 1,7 \\
\hline$I$ & $\infty$ & $\infty$ & $\infty$ & $\infty$ & 1,8 & $\infty$ & $\infty$ & $\infty$ & 0 & 2,4 & $\infty$ \\
\hline$T$ & $\infty$ & $\infty$ & $\infty$ & $\infty$ & $\infty$ & $\infty$ & 1,4 & $\infty$ & 2,4 & 0 & 0,35 \\
\hline & $\infty$ & $\infty$ & $\infty$ & $\infty$ & $\infty$ & $\infty$ & $\infty$ & 1,7 & $\infty$ & 0,35 & 0 \\
\hline
\end{tabular}

Matriks 2. Matriks ketetanggaan dari Graf 1 pada Iterasi 1

\begin{tabular}{|c|c|c|c|c|c|c|c|c|c|c|c|}
\hline & $A$ & $B$ & $C$ & $D$ & $E$ & $F$ & $G$ & $H$ & $I$ & $J$ & $K$ \\
\hline$A[$ & & 0,7 & 1,9 & $\infty$ & 1,35 & $\infty$ & $\infty$ & $\infty$ & $\infty$ & $\infty$ & $\infty$ \\
\hline$B$ & 0,7 & 0 & 1,2 & $\infty$ & 0,65 & $\infty$ & $\infty$ & $\infty$ & $\infty$ & $\infty$ & $\infty$ \\
\hline$C$ & $\infty$ & 1,2 & 0 & 0,6 & $\infty$ & 0,6 & $\infty$ & $\infty$ & $\infty$ & $\infty$ & $\infty$ \\
\hline$D$ & $\infty$ & $\infty$ & 0,6 & 0 & $\infty$ & $\infty$ & 0,65 & $\infty$ & $\infty$ & $\infty$ & $\infty$ \\
\hline$E$ & $\infty$ & 0,65 & $\infty$ & $\infty$ & 0 & 1,2 & $\infty$ & $\infty$ & $\infty$ & $\infty$ & $\infty$ \\
\hline$F$ & $\infty$ & $\infty$ & 0,6 & $\infty$ & 1,2 & 0 & 0,45 & $\infty$ & $\infty$ & $\infty$ & $\infty$ \\
\hline$G$ & $\infty$ & $\infty$ & $\infty$ & 0,65 & $\infty$ & 0,45 & 0 & 0,4 & $\infty$ & 1,4 & $\infty$ \\
\hline$H$ & $\infty$ & $\infty$ & $\infty$ & $\infty$ & $\infty$ & $\infty$ & 0,4 & 0 & $\infty$ & $\infty$ & 1,7 \\
\hline$I$ & $\infty$ & $\infty$ & $\infty$ & $\infty$ & 1,8 & $\infty$ & $\infty$ & $\infty$ & 0 & 2,4 & $\infty$ \\
\hline I & $\infty$ & $\infty$ & $\infty$ & $\infty$ & $\infty$ & $\infty$ & 1,4 & $\infty$ & 2.4 & 0 & 0,35 \\
\hline & & $\infty$ & $\infty$ & $\infty$ & $\infty$ & $\infty$ & $\infty$ & 1,7 & $\infty$ & 0,35 & 0 \\
\hline
\end{tabular}

Matriks 3. Matriks ketetanggaan dari Graf 1 pada Iterasi 2

Untuk $i=1, k=2$, dan $j=5$ diketahui bahwa $W[1,5]=\infty$ dan $W[1,2]+W[2,5]=0,7+0,65=1,35$ sehingga diperoleh,

$$
W[1,5]>W[1,2]+W[2,5]
$$

oleh karena itu pada iterasi selanjutnya, nilai $W[1,5]=1,35$. Adapun matriks ketetanggaan Graf 1 pada

\begin{tabular}{|c|c|c|c|c|c|c|c|c|c|c|c|}
\hline & $A$ & $B$ & C & $D$ & $E$ & $F$ & $G$ & $H$ & $I$ & $J$ & $K$ \\
\hline$A$ & 0 & 0,7 & 1,9 & $\infty$ & 1,35 & $\infty$ & $\infty$ & $\infty$ & $\infty$ & $\infty$ & $\infty$ \\
\hline$B$ & 0,7 & 0 & 1,2 & $\infty$ & 0,65 & $\infty$ & $\infty$ & $\infty$ & $\infty$ & $\infty$ & $\infty$ \\
\hline$C$ & 1,9 & 1,2 & 0 & 0,6 & $\infty$ & 0,6 & $\infty$ & $\infty$ & $\infty$ & $\infty$ & $\infty$ \\
\hline$D$ & $\infty$ & $\infty$ & 0,6 & 0 & $\infty$ & $\infty$ & 0,65 & $\infty$ & $\infty$ & $\infty$ & $\infty$ \\
\hline$E$ & $\infty$ & 0,65 & $\infty$ & $\infty$ & 0 & 1,2 & $\infty$ & $\infty$ & $\infty$ & $\infty$ & $\infty$ \\
\hline$F$ & $\infty$ & $\infty$ & 0,6 & $\infty$ & 1,2 & 0 & 0,45 & $\infty$ & $\infty$ & $\infty$ & $\infty$ \\
\hline$G$ & $\infty$ & $\infty$ & $\infty$ & 0,65 & $\infty$ & 0,45 & 0 & 0,4 & $\infty$ & 1,4 & $\infty$ \\
\hline$H$ & $\infty$ & $\infty$ & $\infty$ & $\infty$ & $\infty$ & $\infty$ & 0,4 & 0 & $\infty$ & $\infty$ & 1,7 \\
\hline$I$ & $\infty$ & $\infty$ & $\infty$ & $\infty$ & 1,8 & $\infty$ & $\infty$ & $\infty$ & 0 & 2,4 & $\infty$ \\
\hline$J$ & $\infty$ & $\infty$ & $\infty$ & $\infty$ & $\infty$ & $\infty$ & 1,4 & $\infty$ & 2,4 & 0 & 0,35 \\
\hline$K$ & $\infty$ & $\infty$ & $\infty$ & $\infty$ & $\infty$ & $\infty$ & $\infty$ & 1,7 & $\infty$ & 0,35 & 0 \\
\hline
\end{tabular}
Iterasi 2 disajikan pada Matriks 3.

Matriks 4. Matriks ketetanggaan dari Graf 1 pada Iterasi 3

Untuk $i=3, k=2$, dan $j=1$ diketahui bahwa $W[3,1]=\infty$ dan $W[3,2]+W[2,1]=1,2+0,7=1,9$ sehingga diperoleh, 


$$
W[3,1]>W[3,2]+W[2,1]
$$

oleh karena itu pada iterasi, nilai $W[3,1]=1,9$. Adapun matriks ketetanggaan Graf 1 pada Iterasi 3 disajikan pada Matriks 4.

Proses iterasi dilanjutkan menggunakan software Matlab, sehingga diperoleh hasil matriks ketetanggaan pada Iterasi 4 atau iterasi akhir disajikan pada Matriks 5.

\begin{tabular}{|c|c|c|c|c|c|c|c|c|c|c|c|}
\hline & $A$ & $B$ & $C$ & $D$ & $E$ & $F$ & $G$ & $H$ & $I$ & $J$ & $K$ \\
\hline & 0 & 0,7 & 1,9 & 2,5 & 1,35 & 2,5 & 2,95 & 3,35 & 6,75 & 4,35 & 4,7 \\
\hline & 0,7 & 0 & 1,2 & 1,8 & 0,65 & 1,8 & 2,25 & 2,65 & 6,05 & 3,65 & 4 \\
\hline & 1,9 & 1,2 & 0 & 0,6 & 1,8 & 0,6 & 1,05 & 1,45 & 4,85 & 2,45 & 2,8 \\
\hline & 2,5 & 1,8 & 0,6 & 0 & 2,3 & 1,1 & 0,65 & 1,05 & 4,45 & 2.05 & 2,4 \\
\hline & 1,35 & 0,65 & 1,8 & 2,3 & 0 & 1,2 & 1,65 & 2,05 & 5,45 & 3,05 & 3,4 \\
\hline & 2,5 & 1,8 & 0,6 & 1,1 & 1,2 & 0 & 0,45 & 0,85 & 4,25 & 1,85 & 2,2 \\
\hline & 2,95 & 2,25 & 1,05 & 0,65 & 1,65 & 0,45 & 0 & 0,4 & 3,8 & 1,4 & 1,75 \\
\hline & 3,35 & 2,65 & 1,45 & 1,05 & 2,05 & 0,85 & 0,4 & 0 & 4,2 & 1,8 & 1,7 \\
\hline & 3,15 & 2,45 & 3,6 & 4,1 & 1,8 & 3 & 3,45 & 3,85 & 0 & 2,4 & 2,75 \\
\hline & 4,35 & 3,65 & 2,45 & 2,05 & 3,05 & 1,85 & 1,4 & 1,8 & 2,4 & 0 & 0,35 \\
\hline & 4,7 & 4 & 2,8 & 2,4 & 3,4 & 2,2 & 1,75 & 1,7 & 2,75 & 0,35 & 0 \\
\hline
\end{tabular}

Matriks 5. Matriks ketetanggaan dari Graf 1 pada Iterasi 4

Sehingga diperoleh jarak minimum dari titik $A$ ke titik $\mathrm{K}$ adalah $4,7 \mathrm{~km}$ dengan rute $\mathrm{A}-\mathrm{B}-\mathrm{C}-\mathrm{F}-\mathrm{G}-$ $\mathrm{J}-\mathrm{K}$. Dengan proses yang sama, diperoleh jarak minimum dari graf pada Gambar 2, Gambar 3, dan Gambar 4 seperti yang tercantum pada Tabel 6.

Tabel 6. Matriks ketetanggaan Graf 1

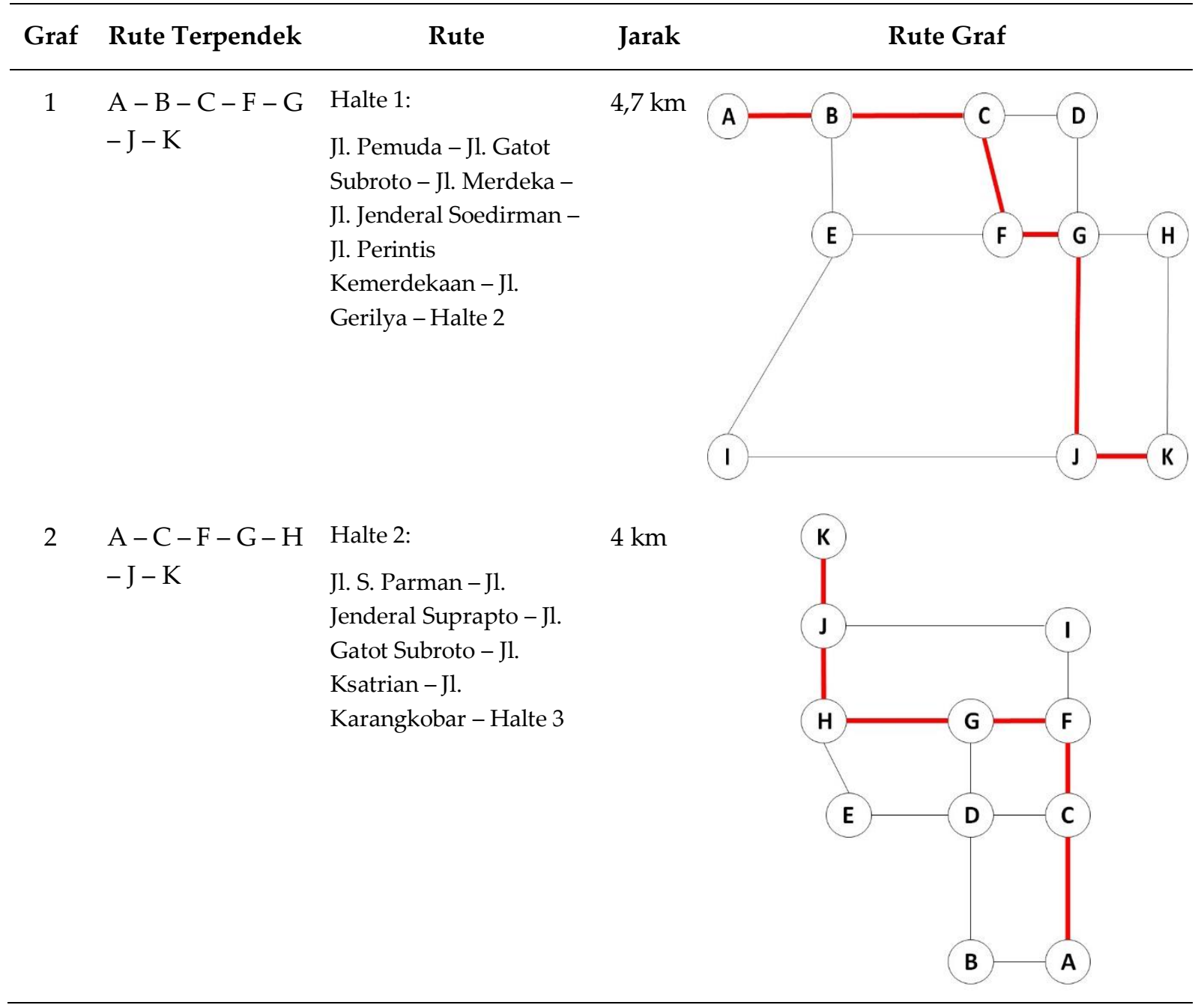


Lanjutan Tabel 6

\begin{tabular}{|c|c|c|c|c|}
\hline Graf & Rute Terpendek & Rute & Jarak & Rute Graf \\
\hline 3 & $\begin{array}{c}A-C-F-G-I \\
-J\end{array}$ & $\begin{array}{l}\text { Halte 3: } \\
\text { Jl. Karangkobar - Jl. } \\
\text { Jatisari - Jl. Riyanto - Jl. } \\
\text { H.R. Bunyamin - Jl. } \\
\text { Raya Baturraden - } \\
\text { Halte } 4\end{array}$ & $5,2 \mathrm{~km}$ & \\
\hline 4 & $A-B-D-E$ & $\begin{array}{l}\text { Halte 7: } \\
\text { Jl. Raya Baturraden } \\
\text { Barat - Jl. Letjen Pol. } \\
\text { Suparto - Jl. Kober - } \\
\text { Halte } 1\end{array}$ & $8,7 \mathrm{~km}$ & \\
\hline
\end{tabular}

Pada penelitian sejenis yang dilakukan oleh Ardiansyah dan Hakim (2012), telah dikaji mengenai pencarian rute terpendek dari suatu titik sembarang ke titik lainnya yang dituju menggunakan algoritma Floyd. Pada penelitian tersebut, titik tujuan merepresentasikan objek wisata. Namun, pada penelitian tersebut belum dikaji mengenai rute terpendek yang menghubungkan antara suatu objek wisata ke objek wisata lainnya. Sementara, pada penelitian ini, kami menggunakan algoritma Floyd, tetapi dengan penambahan penelitian berupa rute terpendek yang menghubungkan antar objek wisata beserta rute yang dapat dilalui. Adapun rute-rute tersebut yaitu sebagai berikut:

1. Rute yang dilalui dari Halte 1 ke Halte 2 adalah Halte 1 - Jalan Pemuda - Jalan Gatot Subroto Jalan Merdeka - Jalan Jenderal Soedirman - Jalan Perintis Kemerdekaan - Jalan Gerilya - Halte 2.

2. Rute yang dilalui dari Halte 2 ke Halte 3 adalah Halte 2 - Jalan S. Parman - Jalan Jenderal Suprapto - Jalan Gatot Subroto - Jalan Ksatrian - Jalan Karangkobar - Halte 3.

3. Rute yang dilalui dari Halte 3 ke Halte 4 adalah Halte 3 - Jalan Karangkobar - Jalan Jatisari - Jalan Riyanto - Jalan H.R. Bunyamin - Jalan Raya Baturraden - Halte 4.

4. Rute yang dilalui dari Halte 4 ke Halte 7 tidak melalui proses pencarian rute terpendek menggunakan algoritma Floyd karena hanya terdapat satu rute yang dapat dilalui oleh bus wisata, yaitu Halte 4 - Jalan Raya Baturraden - Halte 5 - Jalan Raya Baturraden Barat - Halte 6 - Jalan Raya Baturraden Barat - Halte 7.

5. Rute yang dilalui dari Halte 7 kembali ke Halte 1 adalah Halte 7 - Jalan Raya Baturraden Barat Jalan Letjen Pol. Suparto - Jalan Kober - Halte 1. 


\section{Kesimpulan}

Dari hasil pembahasan diketahui bahwa algoritma Floyd dapat digunakan untuk menentukan rute-rute yang dapat dilalui bus wisata dari satu objek wisata ke objek wisata lainnya agar menempuh jarak minimum. Seperti yang telah dipaparkan pada bagian hasil dan pembahasan, rute tersebut saling berkaitan satu sama lainnya karena saling menghubungkan antara objek wisata yang satu dengan objek wisata yang lainnya. Hasil rute terpendek tersebut masih dapat dimaksimalkan dengan cara menambahkan faktor lebar jalan dan kepadatan jalan pada bobot grafnya. Hal tersebut menjadi salah satu saran untuk penelitian selanjutnya.

\section{Ucapan Terima Kasih}

Ucapan terima kasih kami sampaikan kepada rekan-rekan dosen Fakultas Teknik Telekomunikasi dan Elektro, Institut Teknologi Telkom Purwokerto, atas bantuan dan dukungan terhadap penelitian kami. Selain itu, ucapan terima kasih juga kami sampaikan kepada pihak LLDIKTI atas bantuan hibah Penelitian Dosen Pemula yang diberikan kepada kami hingga kami dapat menjalankan penelitian ini dengan lancar tanpa kendala yang berarti.

\section{Referensi}

Ardana, D., \& Saputra, R. (2016). Penerapan Algoritma Dijkstra pada Aplikasi Pencarian Rute Bus Trans Semarang. Seminar Nasional Ilmu Komputer (SNIK 2016) (pp. 299-306). Semarang: Universitas Negeri Semarang.

Ardiansyah, I., \& Hakim, D. K. (2012). Rancang Bangun Aplikasi untuk Menentukan Jalur Terpendek Menggunakan Algoritma Floyd di Lokasi Wisata Purbalingga. JUITA, II(2), 133-143.

Banyumas, B. (2017). Kabupaten Banyumas dalam Angka 2017. Banyumas: Badan Pusat Statistik Kabupaten Banyumas.

Basuki, I., \& Setiadi, A. (2015). Potensi Angkutan Umum Pariwisata Di Daerah Istimewa Yogyakarta. Jurnal Transportasi, 15(2), 135-142.

BPS, B. (2019). Jumlah Kunjungan Wisatawan Mancanegara per Bulan ke Indonesia Menurut Pintu Masuk, 2017-2019. Jakarta: Badan Pusat Statistik. Retrieved September 13, 2019, from https://www.bps.go.id/dynamictable/2018/04/05/1296/jumlah-kunjungan-wisatawanmancanegara-per-bulan-ke-indonesia-menurut-pintu-masuk-2017-2018.html

Darnita, Y., Toyib, R., \& Rinaldi, R. (2017). Implementasi Algoritma Floyd Warshall untuk Menentukan Letak dan Lokasi Perusahaan Travel/Rental Mobil di Kota Bengkulu. Jurnal Pseudocode, IV(2), 144156.

Gusmão, A., Pramono, S. H., \& Sunaryo, S. (2013). Sistem Informasi Geografis Pariwisata Berbasis Web Dan Pencarian Jalur Terpendek Dengan P Algoritma Dijkstra. Jurnal EECCIS, 7(2), 125-130.

Hasibuan, A. R. (2016). Penerapan Algoritma Floyd Warshall untuk Menentukan Jalur Terpendek dalam Pengiriman Barang. Jurnal Riset Komputer (JURIKOM), 3(6), 20-24.

Hermawati, S., \& Hermawati, S. (2016). Potensi Industri Pariwisata Kabupaten Banyumas. Jurnal Ilmiah Ekonomi Bisnis, 21(3), 173-181.

Indiarto, W., \& Somantri, M. (2017). Perancangan Aplikasi Informasi Jadwal dan Rute Bus Rapid Transit Trans Semarang Berbasis Sistem Operasi Android. TRANSMISI, 19(3), 125-137.

Kemenpar, K. (2019). Laporan Kinerja Kementerian Pariwisata Tahun 2018. Jakarta: Kementerian Pariwisata Republik Indonesia. Retrieved September 13, 2019, from http://www.kemenpar.go.id/post/laporan-akuntabilitas-kementerian-pariwisata-lakip-tahun-2018

Kriswanto, Y. R., Bendi, R. K., \& Aliyanto, A. (2014). Penentuan Jarak Terpendek Rute Transmusi dengan Algoritma Floyd-Warshall. Seminar Nasional Teknologi Informasi E Komunikasi Terapan 2014 (SEMANTIK 2014) (pp. 209-216). Semarang: Universitas Dian Nuswantoro.

Munir, R. (2010). Matematika Diskrit. Bandung: Informatika.

Mustika, I. M., Ginardi, R. V., \& Munif, A. (2017). Rancang Bangun Aplikasi Angkutan Trans Sarbagita Provinsi Bali Berbasis Perangkat Bergerak. Jurnal Teknik ITS, 6(1).

Ningrum, F. W., \& Andrasto, T. (2016). Penerapan Algoritma Floyd-Warshall dalam Menentukan Rute Terpendek pada Pemodelan Jaringan Pariwisata di Kota Semarang. Jurnal Teknik Elektro, 8(1), 2124. 
Rifanti, U. M. (2017). Pemilihan Rute Terbaik Menggunakan Algoritma Dijkstra Untuk Mengurangi Kemacetan Lalu Lintas Di Purwokerto. Jurnal Matematika dan Pendidikan Matematika, 2(2), 90-99.

Roselina, R. (2016). Penerapan Algoritma Kruskal dalam Pembangunan Rute Bus Wisata Kota Bandung. Makalah IF2120 Matematika Diskrit.

Sabon, V. L., Perdana, M. T., Koropit, P. C., \& Pierre, W. C. (2018). Strategi Peningkatan Kinerja Sektor Pariwisata Indonesia Pada Asean Economic Community. Esensi: Jurnal Bisnis dan Manajemen, 8(2), 163-176.

Santi, F. (2016). Dampak Aliran Investasi dan Barang/Jasa Pariwisata Internasional Terhadap Permintaan Pariwisata Indonesia. Jurnal Bisnis Darmajaya, 2(2), 105-133.

Setiawan, V., Kiftiah, M., \& Partiwi, W. B. (2017). Analisis Algoritma Floyd Warshall Untuk Menentukan Lintasan Terpendek Pengangkutan Sampah (Studi Kasus: Pengangkutan Sampah di Kabupaten Kubu Raya). Buletin Ilmiah Math. Stat. dan Terapannya (Bimaster), 6(3), 221-230.

Tambunan, N. (2009). Posisi Tranportasi Dalam Pariwisata. Majalah Ilmiah Panorama Nusantara, VI(Januari-Juni), 39-48. 